\title{
The role of joint engagement in the development of language in a community-derived sample of slow-to-talk children
}

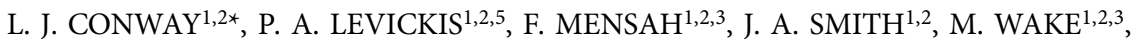 \\ and S. REILLY ${ }^{1,2,4}$ \\ ${ }^{1}$ Murdoch Children's Research Institute, Parkville, Victoria, Australia, ${ }^{2}$ Department of Paediatrics, \\ University of Melbourne, Parkville, Victoria, Australia, ${ }^{3}$ Royal Children's Hospital, Parkville, Victoria, \\ Australia, ${ }^{4}$ Health Executive, Griffith University, Australia, and ${ }^{5}$ Communication and Language Sciences, \\ Newcastle University, Newcastle-upon-Tyne, UK \\ ${ }^{*}$ Corresponding author: Murdoch Children's Research Institute, Flemington Road, Parkville, Victoria 3052, \\ Australia. E-mail: laura.conway@mcri.edu.au
}

(Received 13 December 2016; revised 27 May 2017; accepted 1 May 2018; first published online 21 June 2018)

\begin{abstract}
We explored whether supported (SJE) or coordinated joint engagement (CJE) between mothers recruited from the community and their 24-month-old children who were slow-to-talk at 18 months old were associated with child language scores at ages 24, 36, and 48 months $(n=197)$. We further explored whether SJE or CJE modified the concurrent positive associations between maternal responsive behaviours and language scores. Previous research has shown that SJE, maternal expansions, imitations, and responsive questions were associated with better language scores. Our main finding was that SJE but not CJE was consistently positively associated with 24- and 36-month-old expressive and receptive language scores, but not with 48-month-old language scores. SJE modified how expansions and imitations, but not responsive questions, were associated with language scores; the associations were evident in all but the highest levels of SJE. Further research is necessary to test these findings in other samples before clinical recommendations can be made.
\end{abstract}

Keywords: joint engagement; mother-child interaction; attention; responsivity

\section{Background}

Maternal responsive behaviours used during joint engagement (JE) with their young children predict better language skills (Levickis, Reilly, Girolametto, Ukoumunne, \& Wake, 2014). JE can vary in duration, quality, and in how the child coordinates their attention (Adamson, Bakeman, \& Deckner, 2004; Adamson, Bakeman, Deckner, \& Romski, 2009). To what extent these JE variations are associated with language outcomes, and whether they modify the effect of maternal responsive behaviours on language development, is unclear. Better understanding could inform early language interventions which teach parents to use these responsive behaviours. Since 
unresolved language difficulties are associated with poorer educational, interpersonal, and psychosocial outcomes into adulthood (e.g., Beitchman et al., 2001), improving the efficacy of these interventions is important. The current paper explores the contribution of JE to expressive and receptive language learning both directly and via its effect on maternal responsive behaviours.

Research into maternal behaviours, JE, and language development has tended to examine children with typically developing language and with language delay separately (e.g., D’Odorico \& Jacob, 2006; Paul \& Shiffer, 1991; Rescorla, Bascome, Lampard, \& Feeny, 2001). This truncates the distribution of language abilities considered in each study. The present study focuses on children identified with low expressive vocabulary at an earlier age (18 months compared to 24 months) and below a more liberal vocabulary cut-point (20th compared to 10th percentile) than usual. A large proportion show language scores within the normal range at 24, 36, and 48 months, which is useful for investigating the associations across a wide distribution of language abilities.

JE is when parent and child are actively focused on the same object or event at the same time, and are aware of each other doing so (Adamson \& Bakeman, 1991; Dunham \& Dunham, 1995; Moore \& Dunham, 1995). JE skills, for example pointing, showing, and using eye-contact, are positively associated with language skills (Farrant, Devine, Maybery, \& Fletcher, 2012; Kasari, Gulsrud, Freeman, Paparella, \& Hellemann, 2012; Tomasello \& Todd, 1983). Subsequently, JE difficulties might contribute to problems with language learning (Mundy, Kasari, Sigman, \& Ruskin, 1995). Indeed, children with autism spectrum disorders and late talkers have been found to have difficulties with JE compared with typically developing children (Patterson, Elder, Gulsrud, \& Kasari, 2014; Paul \& Shiffer, 1991; Vuksanovic \& Bjekic, 2013; Wetherby, Yonclas, \& Bryan, 1989).

JE is thought to underpin language acquisition by creating a shared referential framework which helps children make the correct connection between their parent's spoken word and its referent (Akhtar, 2005; Bruner, 1975; Carpenter, Nagell, \& Tomasello, 1998; Tomasello, 2001; Yu \& Ballard, 2007). Within the JE context, children can look at the referent for enough time to learn and practise its word, approximately 1-2 seconds before and after it is spoken (Dixon \& Salley, 2006; Kannass \& Oakes, 2008; Trueswell, Lin, Armstrong, Cartmill, Goldin-Meadow, \& Gleitman, 2016). Hence, variations in how children coordinate their visual attention during JE may explain differences in language learning.

During 'supported' JE (SJE) children visually attend to the shared object only, whilst their parents scaffold the interaction, follow their child's interests, and maintain turns (Adamson et al., 2009). In contrast, during 'coordinated' JE (CJE) children help maintain the interaction by attending to the object and parent, usually by alternating their gaze (Adamson et al., 2009). CJE is therefore likely to tax children's cognitive and affective resources more than SJE (Adamson et al., 2009), and to reduce the time children can look at a spoken word's referent. SJE may therefore provide a better contextual framework for word learning than CJE. Indeed, one small-scale study of typically developing children $(n=56)$ found time in SJE at 18 months old was associated with better expressive and receptive vocabulary scores at 30 months, but time spent in CJE was not (Adamson et al., 2004, 2009). This has yet to be tested in a larger sample or with measures of language skills beyond vocabulary knowledge.

The shared referential framework created in JE gives children the opportunity to benefit from the language-facilitating aspects of maternal responsive behaviours (e.g., 
Diaz, Neal, \& Vachio, 1991). Seminal work by Tomasello and Farrar (1986) demonstrated that maternal verbal input used inside JE at 15 months was correlated with language abilities at 21 months, whilst input used outside JE was not. Previous findings from the sample in the present study showed that maternal responsive behaviours (expansions, imitations, and responsive questions) used during JE at 24 months were positively associated with concurrent child receptive and expressive language scores (Levickis et al., 2014). It is feasible that these associations between responsive behaviours and concurrent language skills might be modified by the JE state in which mother and child are engaged. Specifically, children's sustained attention during SJE may enable them to benefit more from the maternal responsive behaviours than when they are alternating their attention during CJE. However, to date, whether JE state modifies the strength of the association between maternal behaviours and child language skills has not been tested.

\section{Purpose of the current investigation}

The current investigation aimed to answer two questions using a sample of children with language skills spanning the whole language skills distribution:

1. Are supported and coordinated joint engagement at 24 months old associated with receptive and expressive language scores at 24,36 , and 48 months old?

2. Does the level of SJE or CJE modify the association between maternal expansions, imitations, and responsive questions and 24-month-old language scores?

We anticipated that SJE but not CJE would be associated with language outcomes at each age and that the positive associations between maternal responsive behaviours and child language skills at 24 months would be modified by JE status.

\section{Method}

\section{Participants}

The study was nested within a cluster randomized-controlled trial based in a populationlevel survey, Let's Learn Language (NHMRC \#384491) and its follow-up, Language for Learning (NHMRC \#60740) (Wake et al., 2012). Recruitment is described elsewhere (Wake et al., 2011). Participants were recruited at their 12-month-old check-up, offered universally to families in Victoria, Australia. Exclusion criteria were developmental delay, suspected autism spectrum disorder, a major medical condition, or parents with insufficient English to complete questionnaires at grade 6 reading level (typically 11-12 years).

Parents completed a questionnaire at 12 months collecting demographic information. At 18 months, parents completed a screening survey for expressive vocabulary skills, the Sure Start Expressive Language Measure (Roy, Kersley, \& Law, 2005). Children scoring at or below the 20th percentile were invited into a randomised controlled trial (RCT) for a low-intensity parent-toddler language promotion programme $(n=301)$. There were no differences evident in later language outcomes between the intervention and comparison groups (Wake et al., 2011), so the participants are analysed together as a single group in the current study, with all adjusted analyses controlling for intervention group status.

At 24 months, 251 mothers agreed to be video-recorded playing with their child at home. The participants who were and were not video-recorded did not differ in 
demographic characteristics (Levickis et al., 2014). Data were available for 197 participants in the present study: 49 did not consent for their data to be used in other studies, four were excluded after receiving an ASD diagnosis at three or four years, and one was excluded because a caregiver other than the mother took part. There was no evidence that the 197 participants differed from the 251 for whom we had video-recordings, except for maternal age (1.3 years older in this sample).

As shown in Table 1, roughly half of the participants were in the intervention group, half were boys, and half the parents had completed further education. The sample was slightly more socially advantaged than the Australian population on average, evident by a mean Socio-Economic Indexes for Areas (SEIFA) score of disadvantage higher than the Australian mean $(M=1000, S D=100)$. Although the participants had expressive vocabulary scores at or below the 20th percentile at 18 months, their language skills as a group largely normalised, as indicated by face-to-face assessment scores near the normative mean (100) at 24, 36, and 48 months. Moreover, Table 1 shows that only a minority scored 1.25 standard deviations below the mean at 24, 36, and 48 months for either receptive or expressive language, a typical cut-off for identifying language disorder in research (Reilly et al., 2010; Tomblin, Records, Buckwalter, Zhang, Smith, \& O’Brien, 1997).

\section{Procedure}

Parents completed postal questionnaires and participants had face-to-face language assessments in their homes at 24,36 , and 48 months. At 24 months, research assistants, blind to the participants' intervention group status, asked the mothers to play with their children as they normally would for 15 minutes at home using two sets of toys (farmyard and accessories, and doll and accessories). They recorded these interactions onto Sony DVD DS DVD-RW discs using Hitachi DZ-GX5060SW DVD camcorders.

In an earlier study, the recordings were uploaded into Observer XT coding software (Noldus Information Technology, 2008), and the second author coded maternal responsive behaviours used during the middle 10 minutes using a continuous coding methodology (Levickis et al., 2014). There were no differences in these maternal behaviours between the intervention and control group, suggesting that the intervention did not have an effect on mothers' use of these behaviours in the intervention arm of the RCT. For the present study, the middle 5 minutes were observed by the first author (the coder) in Windows Media Player, and SJE and CJE rated.

\section{Measures}

\section{Supported and Coordinated Joint Engagement}

SJE and CJE were rated on a seven-point Likert Scale using two items adapted from Adamson, Bakeman, Deckner, and Nelson (2012), as shown in Table 2. The coder noted the start and end time of each JE episode when mother and child were actively involved with the same object or activity for at least 3 seconds, and whether it was SJE or CJE (based on whether the child looked at or spoke to the mother). The coder noted the interaction's quality by considering the matched affect, energy, and intensity between mother and child, as detailed in the technical manual (Adamson et al., 2012). Finally, the coder estimated the total time in SJE and CJE to select a point on the Likert rating scale. Each point corresponded to an approximate 
Table 1. Sample Characteristics and Summary Language Scores at 24, 36, and 48 months

\begin{tabular}{|c|c|c|}
\hline Sample characteristics & Total $n$ & $n(\%)$ or $M(S D)$ \\
\hline Gender, male & 197 & $103(52.3)$ \\
\hline First-born child & 197 & $73(37.1)$ \\
\hline Birthweight $(g)$ & 190 & $3380.3(620.7)$ \\
\hline SEIFA index score of disadvantage ${ }^{a}$ & 197 & $1026.5(53.3)$ \\
\hline Maternal age at child age 12 months (years) & 197 & $34.3(4.5)$ \\
\hline In intervention arm of trial & 197 & $100(50.7)$ \\
\hline Parent education & 196 & \\
\hline Not completed high school & & $38(19.4)$ \\
\hline Completed high school & & $65(33.2)$ \\
\hline Completed diploma/tertiary qual/postgrad & & $93(47.5)$ \\
\hline \multicolumn{3}{|l|}{ Receptive language score ${ }^{b}$} \\
\hline 24 months & 195 & $90.6(14.0)$ \\
\hline 36 months & 190 & $98.4(15.2)$ \\
\hline 48 months & 193 & $94.7(14.0)$ \\
\hline \multicolumn{3}{|l|}{ Expressive language score ${ }^{b}$} \\
\hline 24 months & 195 & $91.8(12.0)$ \\
\hline 36 months & 189 & $101.1(14.5)$ \\
\hline 48 months & 192 & $97.7(14.3)$ \\
\hline \multicolumn{3}{|l|}{ Low receptive score ${ }^{c}$} \\
\hline 24 months & 195 & $63(32.3)$ \\
\hline 36 months & 190 & $24(12.7)$ \\
\hline 48 months & 193 & $33(17.1)$ \\
\hline \multicolumn{3}{|l|}{ Low expressive score ${ }^{c}$} \\
\hline 24 months & 195 & $27(13.9)$ \\
\hline 36 months & 189 & $16(8.5)$ \\
\hline 48 months & 192 & $26(13.5)$ \\
\hline
\end{tabular}

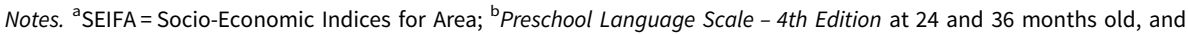
Clinical Evaluation of Language Fundamentals - Preschool 2nd Edition at 48 months old; 'Low language defined as scoring $\geqslant 1.25$ SD below the standardised mean on expressive or receptive language tests.

duration in seconds, based on a 5-minute observation. A rating of one indicated that there were no JE episodes, four indicated that mother and child were in moderatequality JE for about a third of the time or briefly in high-quality JE, and seven that they were frequently in rich and varied JE episodes (Adamson et al., 2012). The rating was increased by one point if the quality was appraised to be high.

To test agreement, $10 \%$ of the samples were independently rated by a second coder (author \#3), blind to the first coder's rating. Unweighted kappas (Cohen, 1960) were 0.5 
and 0.7 for SJE and CJE, respectively. However, no disagreements exceeded one scale point. Consequently, weighted kappas (Cohen, 1968) that counted one-point disagreements as agreements were 1.0 for SJE and CJE. $10 \%$ were also re-rated by the first coder. Intra-rater unweighted kappas were 0.8 and 0.7 for SJE and CJE, respectively, and weighted kappas were 1.0 for both.

\section{Language measures}

The Preschool Language Scale 4th edition (PLS-4; Zimmerman, Steiner, \& Pond, 2002) was administered at 24 and 36 months, and the Clinical Evaluation of Language Fundamentals Preschool - Second edition (CELF-P2; Semel, Wiig, \& Secord, 2006) at 48 months. Subscales from both yield norm-referenced expressive and receptive language standard scores with a mean $(\mathrm{M})$ of 100 and SD of 15 . To more readily compare the different measures in analysis, the scores were rescaled to $z$-scores $(M=0$, $\mathrm{SD}=1)$.

\section{Maternal responsive behaviours}

The maternal responsive behaviours that were the focus of this study, described in Table 3, were expansions (repeats and adds to the child's vocalisation), imitations (repeats the child's vocalisation/verbalisation), and responsive questions (asks wh-questions dependent on child's preceding act). These were chosen because they were each associated with better language scores at 24 and 36 months. The metric used was rate per minute to control for variation in recording duration.

\section{Demographics}

Child, maternal, and environmental information identified as potential confounders a priori were collected in the baseline questionnaire. These were maternal age, parental education, birth order (first or later born), birthweight (as a proxy for biological risk), and gender. Neighbourhood disadvantage was measured using the SEIFA score of disadvantage, calculated using census data about household education, employment and occupation, income, and composition (Australian Bureau of Statistics, 2001). Lower scores indicate greater social disadvantage.

\section{Results}

As shown in Table 4, on average, the participants were engaged in SJE for at least one third of the time (mean rating $=4.1$ ), compared to CJE, in which they were engaged for less than 30 seconds (mean rating $=2.7$ ). This reveals that, as a group, the children spent more time attending to the shared object only whilst playing with their mothers than they spent alternating their gaze between the shared object and their mother. There was no evidence of any differences in SJE or CJE ratings between participants in the intervention or control group of the RCT.

Our first research question asked whether SJE and CJE were associated with receptive and expressive language scores at 24, 36, and 48 months. The correlation matrix in Table 5 shows that higher ratings of SJE, indicating better quality and/or more time spent in SJE, were moderately correlated with better receptive and expressive language scores at 24, 36, and 48 months. As anticipated, there was no consistent evidence for CJE being correlated with language scores.

After checking that the assumption of linearity was met by comparing models fitting SJE and CJE as continuous variables to models fitting them as categorical (divided into 
Table 3. Definitions of Maternal Responsive Communicative Behaviours

\begin{tabular}{lll}
\hline Behaviour & \multicolumn{1}{c}{ Definition } & Example \\
\hline Expansion & $\begin{array}{c}\text { Mother repeats one or all of the child's preceding } \\
\text { words and adds to the child's preceding } \\
\text { verbalisation. }\end{array}$ & $\begin{array}{l}\text { C: "Ball" } \\
\text { M: "It's a red ball" }\end{array}$ \\
\hline $\begin{array}{l}\text { Mother repeats the child's preceding vocalisation } \\
\text { or verbalisation exactly or with a reduction in } \\
\text { the words. }\end{array}$ & $\begin{array}{l}\text { C: "Ball" } \\
\text { M: "Ball" }\end{array}$ \\
\hline $\begin{array}{l}\text { Responsive } \\
\text { Question }\end{array}$ & $\begin{array}{l}\text { Mother asks a wh-question (e.g., what, when, who), } \\
\text { which is immediate and dependent on the } \\
\text { child's preceding act. }\end{array}$ & $\begin{array}{l}\text { Child is playing } \\
\text { with horse } \\
\text { M: "What's that?" }\end{array}$ \\
\hline
\end{tabular}

Table 4. Descriptive Statistics for Supported and Coordinated Joint Engagement and Maternal Use of Responsive Communicative Behaviours

\begin{tabular}{lcc}
\hline Behaviour & $n$ & $M(S D)$ \\
\hline Supported joint engagement (SJE) & 195 & $4.1(1.5)$ \\
\hline Joint engagement rating (1-7) & & \\
\hline Coordinated joint engagement (CJE) & 195 & $2.7(1.3)$ \\
\hline Previously coded responsive behaviours (rate per minute) (Levickis et al., 2014) & \\
\hline Expansion & 197 & $0.6(0.6)$ \\
\hline Imitation & 197 & $0.5(0.5)$ \\
\hline Responsive question & 197 & $0.7(0.5)$ \\
\hline
\end{tabular}

quartiles), unadjusted linear regression models were run. Next, multivariate models adjusted for potential confounders (gender, birthweight, birth order, SEIFA score of disadvantage, parental education, maternal age, RCT intervention group). Finally, to see whether the variability in 36- and 48-month language scores explained by SJE or CJE was independent of the child's earlier language skills, 24-month-old language scores (expressive or receptive as appropriate) were added to the multivariate models (as Adamson et al., 2009).

As shown in Table 6, higher SJE ratings were associated with better receptive and expressive language scores at 24 and 36 months after controlling for confounders. Language scores were approximately $0.2 \mathrm{SD}$ higher for every one-point higher SJE rating. Moreover, Table 6 shows that SJE was associated with 36-month language scores after controlling for 24-month language scores, although the magnitude of this effect was very small. There was evidence that SJE was associated with receptive language scores at 48 months; however, evidence of this association diminished once earlier language skills were included.

As can be seen in Table 6, there was no consistent evidence that CJE was associated with language scores at 24,36 , or 48 months. Although CJE was positively associated with 36-month language scores in the unadjusted models, the effect sizes were small $(<0.2)$, and the associations did not hold once confounders were added.

Our second question asked whether SJE or CJE modified the association between the maternal responsive behaviours (expansions, imitations, responsive questions) and 
Table 5. Correlation Matrix of Maternal Responsive Communicative Behaviours, Joint Engagement, and Child Language Scores at 24, 36, and 48 Months Old

\begin{tabular}{|c|c|c|c|c|c|c|c|c|c|c|}
\hline Variable & 1. & 2. & 3. & 4. & 5. & 6. & 7. & 8. & 9. & 10. \\
\hline \multicolumn{11}{|l|}{ 1. Expansion } \\
\hline 2. Imitation & $.58^{\star \star}$ & & & & & & & & & \\
\hline 3. Responsive Question & $.25^{\star \star}$ & $.28^{\star \star}$ & & & & & & & & \\
\hline 4. SJE & $.29^{\star \star}$ & $.22^{*}$ & $.26^{\star \star}$ & & & & & & & \\
\hline 5. CJE & $.25^{\star \star}$ & $.23^{*}$ & .06 & .11 & & & & & & \\
\hline 6. 24 m Receptive Language & $.35^{\star \star}$ & $.24^{\star \star}$ & $.15^{\star}$ & $.39^{\star \star}$ & .14 & & & & & \\
\hline 7. 24 m Expressive Language & $.40^{\star \star}$ & $.30^{\star \star}$ & $.18^{\star}$ & $.29^{\star \star}$ & .03 & $.61^{\star \star}$ & & & & \\
\hline 8. $36 \mathrm{~m}$ Receptive Language & $.36^{\star \star}$ & $.17^{\star}$ & $.20^{\star}$ & $.35^{\star \star}$ & $.16^{\star}$ & $.67^{\star \star}$ & $.55^{\star \star}$ & & & \\
\hline 9. $36 \mathrm{~m}$ Expressive Language & $.41^{\star \star}$ & $.22^{\star}$ & $.19^{\star}$ & $.34^{\star \star}$ & $.16^{\star}$ & $.67^{\star \star}$ & $.55^{\star \star}$ & $.80^{\star \star}$ & & \\
\hline 10. 48 m Receptive Language & $.31^{\star \star}$ & .14 & .11 & $.26^{\star \star}$ & .12 & $.59^{\star \star}$ & $.41^{\star \star}$ & $.71^{\star \star}$ & $.68^{\star \star}$ & \\
\hline 11. $48 \mathrm{~m}$ Expressive Language & $.34^{\star \star}$ & .13 & .14 & $.20^{*}$ & .06 & $.50^{\star \star}$ & $.40^{\star \star}$ & $.67^{\star \star}$ & $.74^{\star \star}$ & $.74^{\star \star}$ \\
\hline
\end{tabular}

Notes. Items 1-3 are rate per minute, and items 4 and 5 are rated on a 7-point Likert scale; language skills assessed using Preschool Language Scale - 4 th Edition at ages 24 and 36 months, and Clinical Evaluation of Language Fundamentals - Preschool 2 nd Edition at 48 months; ${ }^{\star} p<.1,{ }^{\star \star} p<.05$. 
Table 6. Associations between Joint Engagement State and Receptive and Expressive Language Scores at 24, 36, and 48 Months Old ( $n=195$ )

\begin{tabular}{|c|c|c|c|c|c|c|c|c|c|c|}
\hline \multirow{2}{*}{$\begin{array}{l}\text { Age (months) } \\
\text { Supported JE }\end{array}$} & \multirow[b]{2}{*}{ Language domain ${ }^{a}$} & \multicolumn{3}{|c|}{ Unadjusted } & \multicolumn{3}{|c|}{ Adjusted $^{\mathrm{b}}$} & \multicolumn{3}{|c|}{ Adjusted $^{\mathrm{b}}+24$ month language } \\
\hline & & $\mathrm{ES}^{\mathrm{c}}$ & $95 \% \mathrm{Cl}$ & $\mathrm{R}^{2}$ & $\mathrm{ES}^{\mathrm{c}}$ & $95 \% \mathrm{Cl}$ & $\mathrm{R}^{2}$ & $\mathrm{ES}^{\mathrm{c}}$ & $95 \% \mathrm{Cl}$ & $\mathrm{R}^{2}$ \\
\hline \multirow[t]{2}{*}{24} & Receptive & $0.3^{\star \star \star}$ & $0.2,0.3$ & 0.15 & $0.2^{\star \star \star}$ & $0.2,0.3$ & 0.25 & & & \\
\hline & Expressive & $0.2^{\star \star \star}$ & $0.1,0.3$ & 0.08 & $0.2^{\star \star \star}$ & $0.1,0.3$ & 0.20 & & & \\
\hline \multirow[t]{2}{*}{36} & Receptive & $0.2^{\star \star \star}$ & $0.1,0.3$ & 0.12 & $0.2^{\star \star \star}$ & $0.1,0.3$ & 0.26 & $0.1^{\star}$ & $-0.0,0.2$ & 0.52 \\
\hline & Expressive & $0.2^{\star \star \star}$ & $0.1,0.3$ & 0.11 & $0.2^{\star \star \star}$ & $0.1,0.3$ & 0.25 & $0.1^{\star \star}$ & $0.0,0.2$ & 0.4 \\
\hline \multirow[t]{2}{*}{48} & Receptive & $0.2^{\star \star \star}$ & $0.1,0.3$ & 0.07 & $0.2^{\star \star}$ & $0.1,0.2$ & 0.15 & 0.0 & $-0.1,0.1$ & 0.38 \\
\hline & Expressive & $0.1^{\star \star}$ & $0.0,0.2$ & 0.04 & 0.1 & $-0.0,0.2$ & 0.18 & 0.0 & $-0.1,0.1$ & 0.28 \\
\hline \multicolumn{11}{|l|}{ Coordinated JE } \\
\hline \multirow[t]{2}{*}{24} & Receptive & 0.1 & $-0.0,0.2$ & 0.02 & 0.0 & $-0.1,0.1$ & 0.14 & & & \\
\hline & Expressive & 0.0 & $-0.1,0.1$ & 0.00 & -0.1 & $-0.2,0.0$ & 0.15 & & & \\
\hline \multirow[t]{2}{*}{36} & Receptive & $0.1^{\star \star}$ & $0.0,0.2$ & 0.02 & 0.1 & $-0.1,0.2$ & 0.18 & 0.0 & $-0.1,0.1$ & 0.51 \\
\hline & Expressive & $0.1^{\star \star}$ & $0.0,0.2$ & 0.02 & 0.0 & $-0.1,0.2$ & 0.18 & 0.1 & $-0.0,0.2$ & 0.38 \\
\hline \multirow[t]{2}{*}{48} & Receptive & 0.1 & $-0.0,0.2$ & 0.01 & 0.1 & $-0.1,0.2$ & 0.11 & 0.1 & $-0.1,0.1$ & 0.38 \\
\hline & Expressive & 0.0 & $-0.1,0.2$ & 0.00 & -0.0 & $-0.1,0.1$ & 0.17 & 0.0 & $-0.1,0.1$ & 0.28 \\
\hline
\end{tabular}

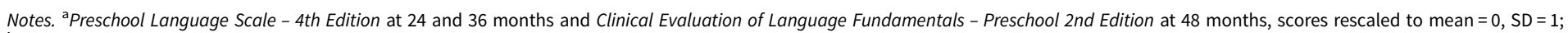
${ }^{b}$ adjusted for child gender, birthweight, birth order, treatment group, neighbourhood disadvantage score (SEIFA), parent education, maternal age; ${ }^{c}$ ES $=$ effect size: interpret as the average standard deviation difference in language score for one point higher rating on SJE or CJE scale; ${ }^{\star} p<.1,{ }^{\star \star} p<.05,{ }^{\star \star \star} p<.001$. 
concurrent child language scores. Since we found no evidence that CJE and language scores were associated, we addressed question two using SJE ratings only.

First, we incorporated an 'SJE by maternal responsive behaviour' interaction term into the models regressing the maternal behaviour on the 24-month-old language scores. These models were compared to models excluding the interaction terms using likelihood ratio tests. As shown in Table 7, only one model supported the interaction term, showing that the association between expansions and 24-month-old receptive language was weaker when SJE ratings were higher (i.e., when more time was spent in SJE). Although a similar pattern can be observed in Table 7 between expansions and expressive language, and between imitations and receptive and expressive language, the interaction terms were not supported. However, because standard tests of interaction can miss subtle effects (Kirkwood \& Sterne, 2013), we fitted simple slopes (UCLA Statistical Group, nd) to explore our question further.

Figure 1 plots the estimated 24-month-old expressive and receptive language scores by maternal expansions, imitations, and responsive questions at each SJE rating (1-7). The positive associations between expansions and imitations and 24-month-old language scores were observed in all but the highest SJE ratings. The associations were weaker at higher SJE ratings, which can also be seen in Table 8. Unlike the other two maternal responsive behaviours, the simple slopes for responsive questions did not support the hypothesis that their association with language scores would differ by SJE rating. There were no SJE levels at which a statistically significant association could be observed (Table 8).

\section{Discussion}

The purpose of this study was to explore: (1) whether SJE and CJE in mother-child interaction at 24 months were associated with language scores at 24,36 , and 48 months, and; (2) whether SJE and CJE modified the positive cross-sectional associations previously found between maternal expansions, imitations, and responsive questions and child language scores (Levickis et al., 2014). We found that SJE was positively associated with 24- and 36-month expressive and receptive language scores, but not consistently with 48-month-old scores. There was no evidence that CJE was consistently associated with language scores at 24,36 , or 48 months. SJE modified how expansions and imitations were associated with cross-sectional language scores, with the associations being evident in all but the highest levels of SJE. In contrast, there was no evidence that SJE modified the association between responsive question and language scores. These findings will be considered in turn, followed by a broader discussion of their contribution to the literature.

\section{Research question 1: the association between JE and language scores}

Our findings expand upon previous research that reported that SJE but not CJE at 18 months was associated with later expressive vocabulary (Adamson et al., 2004, 2009). We found SJE continues to be important to language development at 24 months, and is associated with concurrent language skills as well as skills one year later. Our findings also suggest that time spent in SJE may be important to broader domains of language development than word learning, including comprehension and expressive language more generally. This might be because during SJE children can use their 
Table 7. Interaction Effects of SJE on the Association between Expressive and Receptive Language Score and Maternal Responsive Communicative Behaviours at 24 Months Old

\begin{tabular}{|c|c|c|c|c|}
\hline \multirow[b]{2}{*}{ Maternal behaviour } & \multicolumn{2}{|c|}{ Unadjusted } & \multicolumn{2}{|c|}{ Adjusted $^{a}$} \\
\hline & Coef. $^{b}$ & $95 \% \mathrm{Cl}$ & Coef. $^{\text {b }}$ & $95 \% \mathrm{Cl}$ \\
\hline \multicolumn{5}{|l|}{ Receptive language $^{c}$} \\
\hline Expansions & $-0.12^{\star \star}$ & $-0.24,-0.00$ & -0.10 & $-0.23,0.02$ \\
\hline Imitations & -0.06 & $-0.22,0.10$ & -0.05 & $-0.21,0.11$ \\
\hline Responsive Questions & -0.02 & $-0.17,0.13$ & -0.03 & $-0.20,0.14$ \\
\hline \multicolumn{5}{|l|}{ Expressive language $^{d}$} \\
\hline Expansions & -0.10 & $-0.22,0.02$ & -0.07 & $-0.19,0.06$ \\
\hline Imitations & -0.13 & $-0.30,0.03$ & -0.14 & $-0.30,0.02$ \\
\hline Responsive Questions & 0.01 & $-0.14,0.17$ & 0.04 & $-0.13,0.21$ \\
\hline
\end{tabular}


disadvantage score (SEIFA), parental education, and maternal age; ${ }^{b}$ interaction coefficient and astrix for $p$-value for likelihood ratio test comparing regression model containing the interaction term with regression model without the interaction term; 'language measured using PLS-4 at 24 and 36 months old, CELF-P2 at 48 months old (z-scores); ** $p<.05$.

attentional resources to monitor more than verbal labels, including other aspects of the social interaction. Compared to CJE, whilst in SJE children may have more time to process, consolidate, and learn from their experiences (Hirsh-Pasek et al., 2015). Hence, time in SJE may provide the optimal language-learning environment, at least up to age 36 months.

The finding that SJE was no longer associated with expressive or receptive language scores at 48 months in the final model may indicate that other child, family, or environmental factors become more important to later language development. For example, social disadvantage reportedly becomes more influential in language development between the ages of two and four, perhaps due to an accumulated effect of exposure to poorer language input (Reilly et al., 2010). This 48-month-old finding might be accounted for by a developmental or environmental change common to preschoolers. For example, most Australian children start formal kindergarten at four years old, increasing their exposure to interactions with non-family members, e.g., teachers, peers. These interactions are likely to be important to ongoing language learning. They may become more influential than earlier SJE, and therefore account for greater variability in children's language skills at 48 months.

Regarding CJE, our hypothesis that CJE would not be associated with language outcomes was supported. However, it does leave unanswered the question of what role CJE has in language development (Adamson et al., 2009). After all, young children who use frequent eye-contact and talk directly to their caregivers, both indicators of CJE, are engaging and rewarding to interact with. And an engaged and motivated adult is likely to continue interacting with that child, providing verbal input and feedback important for language development. Perhaps CJE is associated with other aspects of communication or social development that were not examined in this study, such as pragmatic language or social cognition. This is yet to be investigated, to our knowledge. 

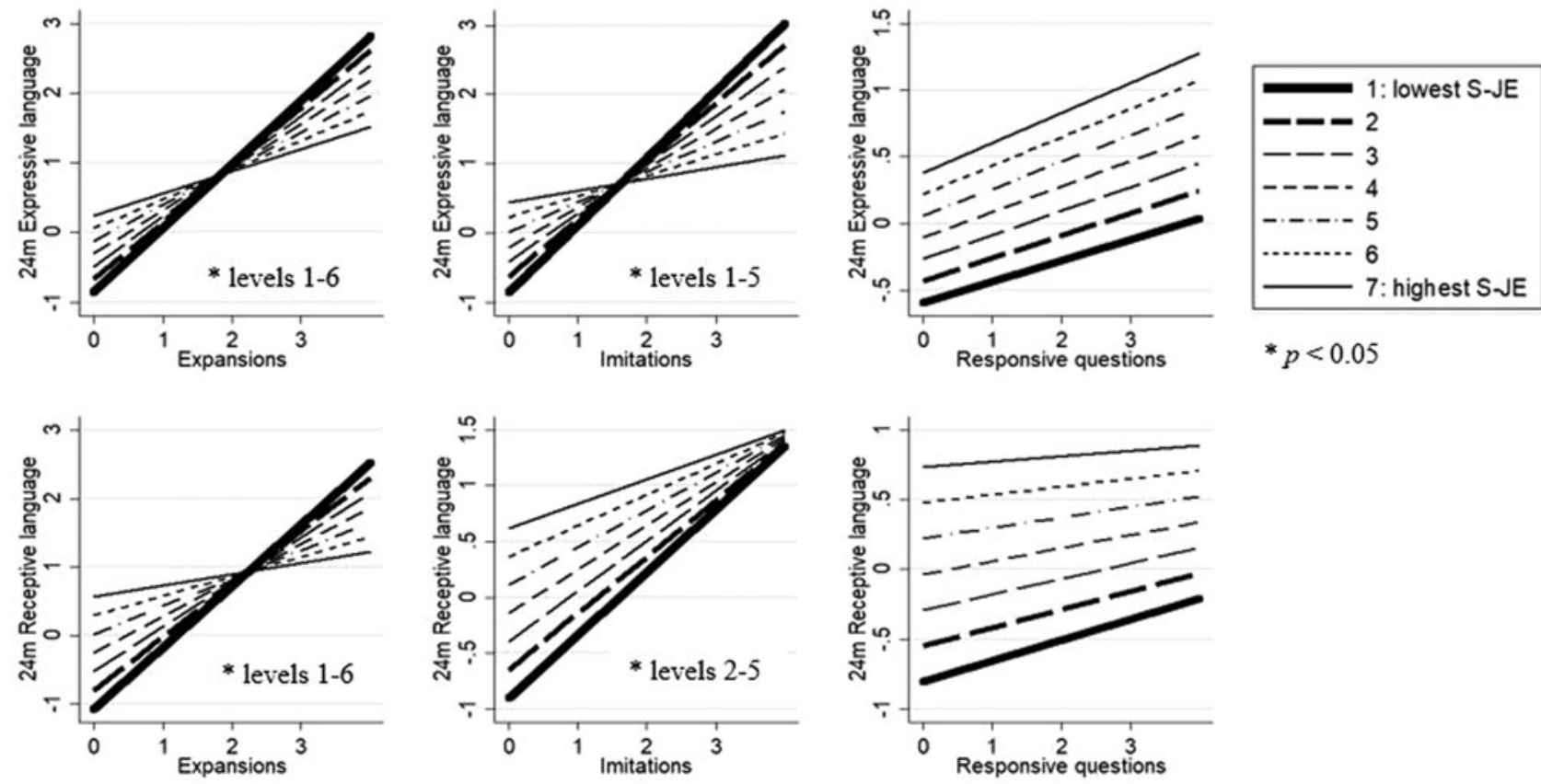

Figure 1. Simple slopes modelling effect modification by Supported Joint Engagement on the associations between maternal behaviours and child language scores at 24 months old (see also Table 8). 
Table 8. Simple Slope Statistics for the Association between Maternal Behaviours and 24-month-old Language Scores by SJE Level (see also Figure 1)

\begin{tabular}{|c|c|c|c|c|}
\hline \multirow[b]{2}{*}{ SJE rating } & \multicolumn{2}{|c|}{ Expressive language } & \multicolumn{2}{|c|}{ Receptive language } \\
\hline & ES & $95 \% \mathrm{Cl}$ & ES & $95 \% \mathrm{Cl}$ \\
\hline \multicolumn{5}{|l|}{ Expansions } \\
\hline 1 & $0.92^{\star \star \star}$ & $0.41,1.43$ & $0.90^{\star \star}$ & $0.40,1.40$ \\
\hline 2 & $0.82^{\star \star \star}$ & $0.42,1.22$ & $0.77^{\star \star \star}$ & $0.38,1.17$ \\
\hline 3 & $0.72^{\star \star \star}$ & $0.42,1.02$ & $0.65^{\star \star \star}$ & $0.36,0.95$ \\
\hline 4 & $0.62^{\star \star \star}$ & $0.39,0.85$ & $0.53^{\star \star \star}$ & $0.30,0.76$ \\
\hline 5 & $0.52^{\star \star \star}$ & $0.30,0.73$ & $0.41^{\star \star \star}$ & $0.20,0.62$ \\
\hline 6 & $0.42^{\star \star}$ & $0.15,0.68$ & $0.29^{\star \star}$ & $0.02,0.55$ \\
\hline 7 & 0.32 & $-0.03,0.67$ & 0.16 & $-0.19,0.51$ \\
\hline \multicolumn{5}{|l|}{ Imitations } \\
\hline 1 & $0.97^{\star \star}$ & $0.33,1.61$ & 0.56 & $-0.07,1.20$ \\
\hline 2 & $0.84^{\star \star}$ & $0.34,1.33$ & $0.51^{\star}$ & $0.02,1.0$ \\
\hline 3 & $0.70^{\star \star \star}$ & $0.33,1.07$ & $0.45^{\star \star}$ & $0.08,0.82$ \\
\hline 4 & $0.57^{\star \star \star}$ & $0.28,0.86$ & $0.39^{\star \star}$ & $0.11,0.68$ \\
\hline 5 & $0.44^{\star \star}$ & $0.16,0.72$ & $0.34^{\star \star}$ & $0.06,0.61$ \\
\hline 6 & 0.30 & $-0.05,0.66$ & 0.28 & $-0.08,0.63$ \\
\hline 7 & 0.17 & $-0.31,0.65$ & 0.22 & $-0.25,0.69$ \\
\hline \multicolumn{5}{|c|}{ Responsive questions } \\
\hline 1 & 0.16 & $-0.44,0.75$ & 0.15 & $-0.43,0.73$ \\
\hline 2 & 0.17 & $-0.29,0.63$ & 0.13 & $-0.32,0.58$ \\
\hline 3 & 0.18 & $-0.17,0.52$ & 0.11 & $-0.22,0.45$ \\
\hline 4 & 0.19 & $-0.08,0.46$ & 0.09 & $-0.17,0.35$ \\
\hline 5 & 0.20 & $-0.07,0.47$ & 0.08 & $-0.19,0.34$ \\
\hline 6 & 0.21 & $-0.13,0.56$ & 0.06 & $-0.28,0.40$ \\
\hline 7 & 0.22 & $-0.24,0.69$ & 0.04 & $-0.41,0.49$ \\
\hline
\end{tabular}

Notes. ES = Estimated effect size for the association between maternal behaviour and concurrent language at each level of SJE; ${ }^{\star} p<.1,{ }^{\star \star} p<.05,{ }^{* \star} p<.001$.

\section{Research question 2: JE as an effect modifier}

The second aim of this paper was to examine whether SJE or CJE modified the associations previously found in this sample between maternal responsive behaviours and language outcomes (Levickis et al., 2014). Whilst CJE was not found to be associated with language outcomes, SJE was observed to modify the association between maternal expansions and imitations and concurrent language outcomes, but not responsive questions. 
Maternal expansions and imitations were positively associated with receptive and expressive language scores at all but the highest levels of SJE. At these highest ratings, mother and child are frequently in rich and varied SJE where maternal behaviours may not have the same potential to influence an already optimal language-learning environment. The simple slopes illustrate that, even though the association between the expansions and imitations and child language scores is observed at most levels of SJE, the strength of the association is greatest at the lower ratings. This is when the child is spending less time in SJE. Where SJE is less frequent or of lower quality, expanding upon or imitating a child's utterance may be especially important.

We found no evidence that SJE modified the association with responsive questions. This might be an artefact of the coding protocol for SJE and CJE. A responsive question necessitates a response from the child. The child's response may lead to a transition in engagement state. For example, if the child answers the question whilst continuing to play with the object and glancing at or responding to their mother, their engagement state will become 'coordinated' and the SJE episode will end. If the child does not respond, the mother might terminate the SJE episode depending on her interpretation of the child's non-response. Therefore, the reason why we did not observe an effect modification could be that, regardless of the child's level of SJE, maternal responsive questions usually results in SJE ending. An alternative explanation could be that the association between some maternal behaviours and child language is more stable than others and less likely to be modified by the interactional context in which they are used. For example, the degree to which the maternal behaviour is dependent on the child's preceding behaviour, and hence stage of language development, might be important. Expansions and imitations can only be used in response to a child's preceding verbalisation or vocalisation. In comparison, responsive questions can be asked about anything the child is attending to, regardless of the child's verbalisations or vocalisations. Therefore, use of responsive questions depends less on the child's behaviour, and more on the mother's ability to create opportunities to initiate or maintain the conversation. It might be that maternal responsive behaviours that proactively create these conversational opportunities have the more stable association with language development regardless of the interactional context. Further exploration of the characteristics of maternal behaviours is required to explore these ideas further.

\section{Study strengths and limitations}

Study strengths include the large sample size, the prospective, community-based design, the observational measure of SJE and CJE, and repeated face-to-face language assessments. Observational and direct measures can provide a more objective measure than parent report (Hayden, Durbin, Klein, \& Olino, 2010). Recording the mother-child playing in the home may also have increased the likelihood of capturing a naturalistic interaction. Finally, the concurrent measures of language skills and JE enabled analytical adjustment for child language ability at the time of the interaction.

Our sample was neither strictly a general population sample, nor a typical late talker sample. It is possible that the parent-child interactions may have been qualitatively different from interactions between parents and children who did not have low expressive vocabulary at 18 months, or those between parents and late talkers. We 
also cannot rule out that the reason we replicated an earlier study that examined SJE in 18-month-olds (Adamson et al., 2004) was that our sample may have delayed JE skills related to their slower expressive vocabulary acquisition. Caution is therefore required in generalising the findings to a general population sample or a late talker sample.

Socially disadvantaged households were under-represented in our sample, despite efforts to recruit from across socioeconomic areas. This is often the case in longitudinal studies (Kiernan \& Mensah, 2009), and may mean that the full range of parent-child interactions was not captured, particularly those disproportionately affected by family stress. The change in language measure at 48 months, from the PLS-4 to the CELF-P2, means that there is the potential for introduced nonequivalence. The change in association between SJE and language scores at 48 months may be due to this change in language measure.

Finally, the quantity of child-directed speech heard by the children during the interaction and during each JE episode was not calculated. It was therefore not possible to quantify the strength of the associations between JE, maternal behaviours, and child language scores over and above maternal input quantity and diversity (McGillion, Pine, Herbert, \& Matthews, 2017).

\section{Future directions}

Further investigation is necessary before drawing clinical recommendations from this study. However, possibilities include trialling a version of the SJE scale to use within clinical assessment to identify a child's abilities to participate in interactions that are optimal for language learning. Further, investigating how SJE and CJE are associated with existing measures of child attentional skills to determine what additional skills are being captured by the JE ratings over and above attention skills would be helpful. Understanding which maternal behaviours are modified by SJE, and which are not, might be useful for clinicians tailoring individual intervention strategies for young children. Finally, these findings suggest that the supported or scaffolded characteristics of joint engagement may be especially important to language learning at 24 months, rather than just the joint engagement alone. By having little responsibility for orchestrating turns or monitoring their mother's interests, the child can take full advantage of the shared attention for language learning. Greater understanding of this scaffolding might inform language promotion approaches to coaching caregivers on how best to support their toddlers during interactions.

\section{Conclusions}

This investigation has brought together two separate but related strands of research into child language development; research into the parent-child interactional context, and research into specific types of maternal input. We found that time spent in SJE at 24 months made an important contribution to the language-learning environment up to the age of 36 months, and to the beneficial outcomes associated with some maternal responsive behaviours used within this environment. Future research should progress this approach with the intention of improving the efficacy of early language intervention strategies.

Supplementary Materials. For Supplementary Materials for this paper, please visit $<$ https://doi.org/10. 1017/S030500091800017X>. 
Acknowledgements. Let's Learn Language (NHMRC Strategic Award 384491) and Language for Learning (NHMRC Project Grant 607407) were funded by the Australian National Health and Medical Research Council. Manuscript preparation was supported by the NHMRC-funded Centre of Research Excellence in Child Language (\#1023493), an Australian Government Research Training Program Scholarship (previously known as an Australian Postgraduate Award), and an MCRI top-up scholarship for LC, and an NHMRC Practitioner Fellowship for SR (\#1041892). FM has been supported by an NHMRC Early Career Fellowship (\#1037449), an NHMRC Career Development Fellowship (\#1111160), and research at the Murdoch Children's Research Institute supported by the Victorian Government's Operational Infrastructure Support Program. We thank Professor Edith Bavin for her advice, and Dr Sherryn Tobin and Ms Hannah Bryson for data collection. We sincerely thank the participants and their families.

\section{References}

Adamson, L. B., \& Bakeman, R. (1991). The development of shared attention during infancy. In R. Vasta (Ed.), Annals of child development (Vol. 8, pp. 1-41). London: Jessica Kingsley Publishers.

Adamson, L. B., Bakeman, R., \& Deckner, D. F. (2004). The development of symbol-infused joint engagement. Child Development, 75(4), 1171-87.

Adamson, L. B., Bakeman, R., Deckner, D. F., \& Nelson, P. B. (2012). Rating parent-child interactions: joint engagement, communication dynamics, and shared topics in autism, Down syndrome, and typical development. Journal of Autism and Developmental Disorders, 42(12), 2622-35.

Adamson, L. B., Bakeman, R., Deckner, D. F., \& Romski, M. (2009). Joint engagement and the emergence of language in children with autism and Down syndrome. Journal of Autism and Developmental Disorders, 39(1), 84-96.

Akhtar, N. (2005). Is joint attention necessary for early language learning? In B. D. Homer \& C. S. TamisLeMonda (Eds.), The development of social cognition and communication (pp. 165-79). Mahwah, NJ: Lawrence Erlbaum Associates.

Australian Bureau of Statistics (ABS) (2001). Socio-economic indexes for areas. Canberra: Australian Bureau of Statistics.

Beitchman, J. H., Wilson, B., Johnson, C. J., Atkinson, L., Young, A., Adlaf, E., ... Douglas, L. (2001). Fourteen-year follow-up of speech/language-impaired and control children: psychiatric outcome. Journal of the American Academy of Child and Adolescent Psychiatry, 40(1), 75-82.

Bruner, J. S. (1975). From communication to language - psychological perspective. Cognition, 3(3), 255-87.

Carpenter, M., Nagell, K., \& Tomasello, M. (1998). Social cognition, joint attention, and communicative competence from 9 to 15 months of age. Monographs of the Society for Research in Child Development, 63(4), 176.

Cohen, J. (1960). A coefficient of agreement for nominal scales. Educational and Psychosocial Measurement, 20, 37-46.

Cohen, J. (1968). Weighted kappa: nominal scale agreement provision for scaled disagreement or partial credit. Psychological Bulletin, 70(4), 213-20.

Diaz, R. M., Neal, C. J., \& Vachio, A. (1991). Maternal teaching in the zone of proximal development: a comparison of low and high-risk dyads. Merrill-Palmer Quarterly, 83-107.

Dixon, W. E., \& Salley, B. J. (2006). "Shhh! We're tryin' to concentrate": attention and environmental distracters in novel word learning. Journal of Genetic Psychology, 167(4), 393-414.

D’Odorico, L., \& Jacob, V. (2006). Prosodic and lexical aspects of maternal linguistic input to late-talking toddlers. International Journal of Language \& Communication Disorders, 41(3), 293-311.

Dunham, P. J., \& Dunham, F. (1995). Optimal social structures and adaptive infant development. In C. Moore \& P. J. Dunham (Eds.), Joint attention: its origins and role in development (pp. 159-88). Hillsdale, NJ: Lawrence Erlbaum Associates.

Farrant, B. M., Devine, T. A. J., Maybery, M. T., \& Fletcher, J. (2012). Empathy, perspective-taking and prosocial behaviour: the importance of parenting practices. Infant and Child Development, 21(2), $175-88$

Hayden, E. P., Durbin, C. E., Klein, D. N., \& Olino, T. M. (2010). Maternal personality influences the relationship between maternal reports and laboratory measures of child temperament. Journal of Personality Assessment, 92(6), 586-93. 
Hirsh-Pasek, K., Adamson, L. B., Bakeman, R., Owen, M. T., Golinkoff, R. M., Pace, A., ... Suma, K. (2015). The contribution of early communication quality to low-income children's language success. Psychological Science, 26(7), 1071-83.

Kannass, K. N., \& Oakes, L. M. (2008). The development of attention and its relations to language in infancy and toddlerhood. Journal of Cognition and Development, 9(2), 222-46.

Kasari, C., Gulsrud, A., Freeman, S., Paparella, T., \& Hellemann, G. (2012). Longitudinal follow-up of children with autism receiving targeted interventions on joint attention and play. Journal of the American Academy of Child \& Adolescent Psychiatry, 51(5), 487-95.

Kiernan, K. E., \& Mensah, F. K. (2009). Poverty, maternal depression, family status and children's cognitive and behavioural development in early childhood: a longitudinal study. Journal of Social Policy, 38(4), 569-88.

Kirkwood, B. R., \& Sterne, J. A. C. (2013). Essential medical statistics, 2nd ed. Malden, MA: Blackwell Science.

Levickis, P., Reilly, S., Girolametto, L. E., Ukoumunne, O. C., \& Wake, M. (2014). Maternal behaviors promoting language acquisition in slow-to-talk toddlers: prospective community-based study. Journal of Developmental and Behavioral Pediatrics, 35(4), 274-81.

McGillion, M., Pine, J. M., Herbert, J. S., \& Matthews, D. (2017). A randomised controlled trial to test the effect of promoting caregiver contingent talk on language development in infants from diverse socioeconomic status backgrounds. Journal of Child Psychology and Psychiatry, 58(10), 1122-31.

Moore, C., \& Dunham, P. J. (1995). Joint attention: its origins and role in development. Hillsdale, NJ: Lawrence Erlbaum Associates.

Mundy, P., Kasari, C., Sigman, M., \& Ruskin, E. (1995). Non-verbal communication and early language acquisition in children with Down's Syndrome and in normally developing children. Journal of Speech, Language, and Hearing Research, 38(1), 157-67.

Noldus Information Technology (2008). The Observer XT (Version 8.0). The Netherlands Retrived from $<$ https://www.noldus.com/human-behavior-research/products/the-observer-xt>.

Patterson, S. Y., Elder, L., Gulsrud, A., \& Kasari, C. (2014). The association between parental interaction style and children's joint engagement in families with toddlers with autism. Autism, 18(5), 511-18.

Paul, R., \& Shiffer, M. E. (1991). Communicative initiations in normal and late-talking toddlers. Applied Psycholinguistics, 12(4), 419-31.

Reilly, S., Wake, M., Ukoumunne, O. C., Bavin, E., Prior, M., Cini, E., ... Bretherton, L. (2010). Predicting language outcomes at 4 years of age: findings from Early Language in Victoria Study. Pediatrics, 126(6), e1530-e1537.

Rescorla, L., Bascome, A., Lampard, J., \& Feeny, N. (2001). Conversational patterns in late-talkers at age 3. Applied Psycholinguistics, 22(2), 235-51.

Roy, P., Kersley, H., \& Law, J. (2005). The Sure Start language measure standardisation study. Retrieved from <http://webarchive.nationalarchives.gov.uk/20090608190656/http://www.surestart.gov.uk/publications/ index.cfm?document $=1460>$.

Semel, E., Wiig, E. H., \& Secord, W. A. (2006). The Clinical Evaluation of Language FundamentalsPreschool, Second Edition (CELF-P2): Australian Standardised Edition. NSW: Harcourt Assessment Inc.

Tomasello, M. (2001). Perceiving intentions and learning words in the second year of life. In M. Bowerman \& S. C. Levinson (Eds.), Language acquisition and conceptual development (No. 3, pp. 132-158). Cambridge University Press.

Tomasello, M., \& Farrar, M. J. (1986). Joint attention and early language. Child Development, 57(6), 1454-63.

Tomasello, M., \& Todd, J. (1983). Joint attention and lexical acquisition style. First Language, 4, $197-212$.

Tomblin, J. B., Records, N. L., Buckwalter, P., Zhang, X. Y., Smith, E., \& O’Brien, M. (1997). Prevalence of specific language impairment in kindergarten children. Journal of Speech, Language, and Hearing Research, 40(6), 1245-60.

Trueswell, J. C., Lin, Y., Armstrong, B., Cartmill, E. A., Goldin-Meadow, S., \& Gleitman, L. R. (2016). Perceiving referential intent: dynamics of reference in natural parent-child interactions. Cognition, 148, 117-35.

UCLA Statistical Consulting Group (nd). How can I explain a continuous by continuous interaction? Stata FAQ. Retrieved from <https://stats.idre.ucla.edu/stata/faq/how-can-i-explain-a-continuous-bycontinuous-interaction-stata-12/>. 
Wake, M., Levickis, P., Tobin, S., Zens, N., Law, J., Gold, L., ... Reilly, S. (2012). Improving outcomes of pre-school language delay in the community: protocol for the Language for Learning randomised controlled trial. BMC Pediatrics, 12, 1-11.

Wake, M., Tobin, S., Girolametto, L. E., Ukoumunne, O. C., Gold, L., Levickis, P., ... Reilly, S. (2011). Outcomes of population-based language promotion for slow-to-talk toddlers at ages two and three years: Let's Learn Language cluster randomised controlled trial. BMJ, 343, d4741-d4741.

Wetherby, A. M., Yonclas, D. G., \& Bryan, A. A. (1989). Communicative profiles of preschool-children with handicaps: implications for early identification. Journal of Speech and Hearing Disorders, 54(2), $148-58$.

Vuksanovic, J., \& Bjekic, J. (2013). Developmental relationship between language and joint attention in late talkers. Research in Developmental Disabilities, 34(8), 2360-8.

Yu, C., \& Ballard, D. H. (2007). A unified model of early word learning: integrating statistical and social cues. Neurocomputing, 70(13), 2149-65.

Zimmerman, I. L., Steiner, V. G., \& Pond, R. E. (2002). The Preschool Language Scale, 4th Edition. San Antonio, TX: Psychological Corporation.

Cite this article: Conway LJ, Levickis PA, Mensah F, Smith JA, Wake M, Reilly S (2018). The role of joint engagement in the development of language in a community-derived sample of slow-to-talk children. Journal of Child Language 45, 1275-1293. https://doi.org/10.1017/S030500091800017X 